\title{
Surface chemistry of gold nanoparticles produced by laser ablation in pure and saline water
}

Anna Lévy, ${ }^{* \dagger}$ Manuel De Anda Villa, ${ }^{\dagger}$ Gaétan Laurens, ${ }^{\dagger}$ Valérie Blanchet, ${ }^{\Uparrow}$ John

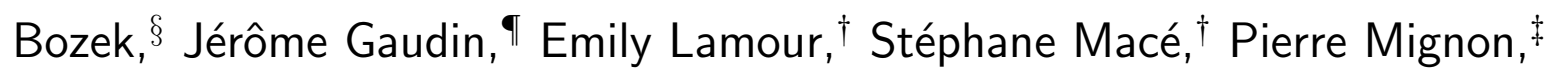
Aleksandar R. Milosavljević, ${ }^{\S}$ Christophe Nicolas,,$^{\S}$ Minna Patanen,, Christophe Prigent, ${ }^{\dagger}$ Emmanuel Robert,,$\S$ Sébastien Steydli, ${ }^{\dagger}$ Martino Trassinelli, ${ }^{\dagger}$ Dominique Vernhet, ${ }^{\dagger}$ Onni Veteläinen, ${ }^{\prime}$ and David Amans ${ }^{\ddagger}$

$\dagger$ Institut des Nanosciences de Paris, Sorbonne Université, Campus Pierre et Marie Curie, CNRS UMR7588, 75005 Paris, France

$\ddagger$ Université Claude Bernard Lyon 1, UMR5306 CNRS, Institut Lumière Matière, University of Lyon, F-69622 Villeurbanne, France

\CNRS, CEA, CELIA (Centre Lasers Intenses et Applications), University of Bordeaux, UMR5107, F-33405 Talence, France

$\S L$ 'Orme des Merisiers, Synchrotron SOLEIL, Saint-Aubin, BP 48, F-91192 Gif-sur-Yvette Cedex, France

$\|$ Nano and Molecular Systems Research Unit, Faculty of Science, University of Oulu, P.O. Box 3000, FI-90014 Oulu, Finland

E-mail: levy@insp.jussieu.fr

\section{Contents}

Experimental XPS parameters 


\section{Experimental XPS parameters}

The experimental parameters used to record $\mathrm{Au} 4 \mathrm{f}$ and $\mathrm{Br} 3 \mathrm{~d}$ spectra on the Alkaline, $\mathrm{NaBr}$ and $\mathrm{NaBr}^{W}$ samples are reported in Table $\mathrm{S} 1$.

Table S1: Experimental parameters of the XPS spectra measurements (monochromator slit width (Mono. slit), electron energy analyzer pass energy (pass), resulting overall spectral resolution $(\Delta E)$, indication of a background subtraction (Bkg. sub.), calculated effective electron attenuation length (EAL) in gold nanoparticles ${ }^{1,2}$ ).

\begin{tabular}{|c|c|c|c|c|c|c|}
\hline & Core level & \multicolumn{3}{|c|}{$\mathrm{Au} 4 \mathrm{f}$} & $\operatorname{Br} 3 \mathrm{~d}$ & Valence \\
\hline Sample & $\mathrm{h} \nu(\mathrm{eV})$ & 210 & 525 & 650 & 210 & 100 \\
\hline \multirow{5}{*}{ Alkaline } & Mono. slit $(\mu \mathrm{m})$ & 600 & 150 & - & - & 600 \\
\hline & pass (eV) & 200 & 200 & - & - & 200 \\
\hline & $\Delta E(\mathrm{meV})$ & 640 & 640 & - & - & 430 \\
\hline & Bkg. sub. ? & $\mathrm{y}$ & $\mathrm{n}$ & - & - & $\mathrm{y}$ \\
\hline & EAL (nm) & 0.21 & 0.40 & - & - & 0.19 \\
\hline \multirow{5}{*}{$\mathrm{NaBr}$} & Mono. slit $(\mu \mathrm{m})$ & 600 & 150 & 115 & 300 & 600 \\
\hline & pass $(\mathrm{eV})$ & 200 & 200 & 200 & 100 & 200 \\
\hline & $\Delta E(\mathrm{meV})$ & 640 & 640 & 665 & 320 & 430 \\
\hline & Bkg. sub. ? & $\mathrm{y}$ & $\mathrm{n}$ & $\mathrm{n}$ & $\mathrm{n}$ & $\mathrm{y}$ \\
\hline & EAL (nm) & 0.21 & 0.40 & 0.47 & 0.22 & 0.19 \\
\hline \multirow{4}{*}{$N a B r^{W}$} & "Mono. slit $(\mu \mathrm{m})$ & 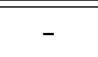 & - & 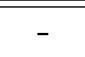 & 300 & 600 \\
\hline & pass $(\mathrm{eV})$ & - & - & - & 100 & 200 \\
\hline & $\Delta E(\mathrm{meV})$ & - & - & - & 320 & 430 \\
\hline & Bkg. sub. ? & - & - & - & $\mathrm{n}$ & $\mathrm{n}$ \\
\hline
\end{tabular}

\section{Investigation of nanoparticle surface contamination}

The atomizing and nanoparticle beam generation processes can bring various sources of nanoparticle surface contamination that are reduced to the minimum in this experiment. For that purpose, we use high purity Ar as a carrier gas, minimize the length of path of 
the aerosol to the entrance of the aerodynamic lens (which is in vacuum), and we clean the atomiser setup carefully between the samples. However, we have observed that aerosol experiments are prone to have some contamination of volatile organosiloxanes conductive silicone tubing used to connect the atomiser to the dryers and the dryers to the vacuum setup (around $60 \mathrm{~cm}$ during this experiment). This contamination has also been observed for different types of nanoparticles measured with similar setup (salt, ${ }^{3}$ metal, and carbonaceous ${ }^{4}$ nanoparticles). Based on these previous observations, we have also investigated this issue by recording the Si $2 p$ core level as reported in Figure S1. The spectrum represented with a black line is obtained by subtracting the "gas phase" spectrum (perimeter of the detector image) from a "gas phase + nanoparticle" spectrum (middle of the detector image). This result demonstrates that the Si contamination is in solid phase since it remains after gasphase component subtraction. One could therefore raise two different hypotheses: (1) this contamination is due to independent nanoparticles flying through the ADLS system or (2) this contamination is present on the gold nanoparticle surface.

The first hypothesis can be most probably ruled out since no other kind of nanoparticles have been observed on the TEM grids after the ADLS and, the Si $2 p$ signal is not present when only water or saline water is used in the atomizer.

The second, most probable, hypothesis, i.e. organosiloxanes bonded to the Au NPs, leads therefore to the following important question: does this contamination can affect the nanoparticle surface characteristics and, more especially, its surface oxidation ? We can very safely exclude any effective influence of the contamination since these organosiloxanes molecules are only physisorbed on the Au nanoparticle surface. Indeed, given the comparable photoionization cross-sections of $\mathrm{Au} 4 \mathrm{f}$ and Si 2p (2.6 and 2.7 Mbarn respectively) and their comparable intensities in Figure S1, one should clearly observe a Au 4 f doublet associated to Au-Si chemical bonds expected to be shifted by about $1 \mathrm{eV}$ to higher binding energies with respect to the main one. ${ }^{5,6}$ Its obvious absence (also on figure 5 of the main manuscript) accounts for a simple physisorption of this pollution which therefore cannot be responsible 
of any modification of the surface oxidation.

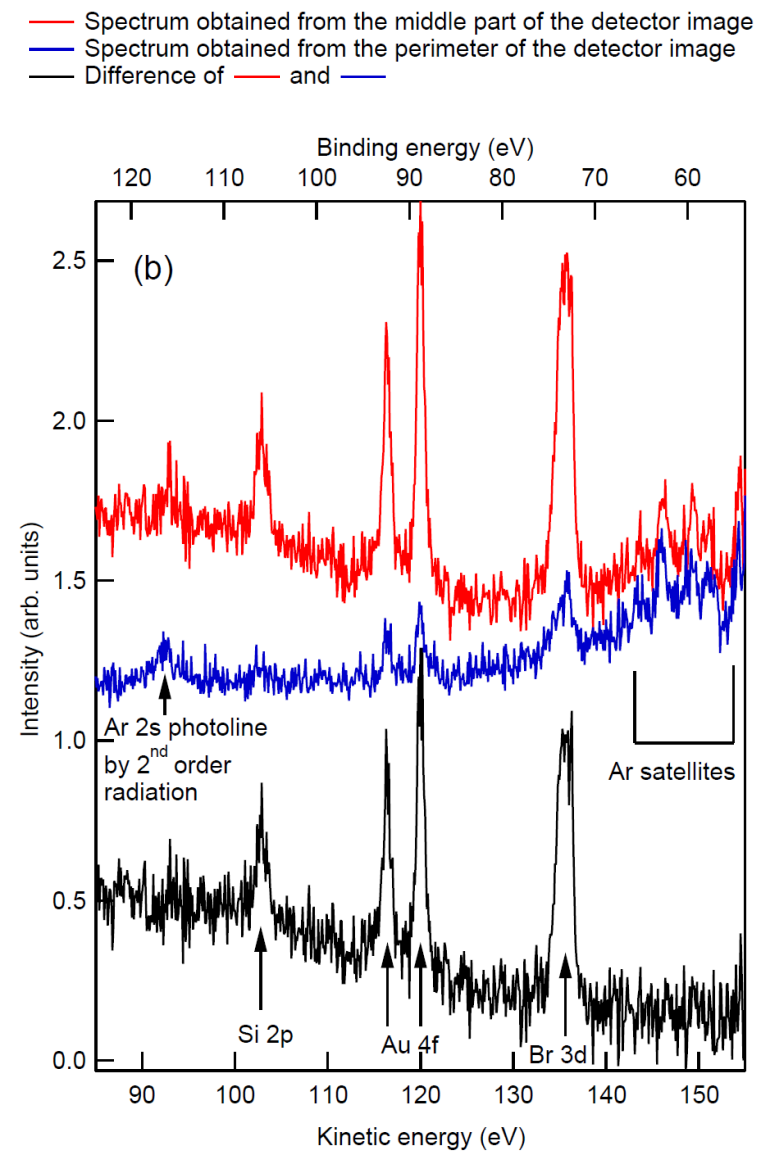

Figure S1: Si 2p XPS spectrum collected for 20 sweeps. Si 2p and Au $4 \mathrm{f}$ having similar photoionisation cross-sections at $210 \mathrm{eV}$, a chemically adsorbed pollution of organosiloxane pollution on the NP should have been revealed as an extra doublet at higher binding energy with respect to the main component (about $+1 \mathrm{eV}$ ). The lack of such extra component leads us to conclude that this contamination is only due to physisorbed molecules and as so, can not influence the oxidation of the Au NP surface of the pristine sample.

\section{Numerical computation: effect of the counterion $\mathrm{Na}^{+}$}

Numerical simulations have been performed to evaluate the role of the $\mathrm{Na}^{+}$counterion. The calculations reported in the main manuscript systematically includes $\mathrm{Na}^{+}$while in this section we report the case of halide adsorption with no counterion (Table S2). Figure S2 summarizes the studied configurations for this comparison. 
Table S2: Adsorption energies $[\mathrm{eV}]$ of halide anions $\mathrm{X}^{-}\left(\mathrm{F}^{-}, \mathrm{Cl}^{-}, \mathrm{Br}^{-}\right.$and $\left.\mathrm{I}^{-}\right)$on $\mathrm{Au}\{111\}$ facets without counterions $\mathrm{Na}^{+}$. The presence of oxides $\left(\mathrm{OH}^{-}\right.$or $\left.\mathrm{O}^{2-}\right)$ on the adsorption energy is evaluated. A positive value corresponds to an energetically unfavorable adsorption of the halide anions $\mathrm{X}^{-}$.

\begin{tabular}{l|cccc} 
Surface & $\mathrm{F}^{-}$ & $\mathrm{Cl}^{-}$ & $\mathrm{Br}^{-}$ & $\mathrm{I}^{-}$ \\
\hline $\mathrm{Au}\{111\}$ & 3.76 & 4.23 & 4.29 & 4.32 \\
$\mathrm{Au}\{111\}-\mathrm{OH}^{-}$ & 3.76 & 4.23 & 4.30 & 4.33 \\
$\mathrm{Au}\{111\}-\mathrm{O}^{2-}$ & 3.79 & 4.22 & 4.33 & 4.31
\end{tabular}

Table S3: Adsorption energies $[\mathrm{eV}]$ of halide anions $\mathrm{X}^{-}\left(\mathrm{F}^{-}, \mathrm{Cl}^{-}, \mathrm{Br}^{-}\right.$and $\left.\mathrm{I}^{-}\right)$on $\mathrm{Au}$ $\{111\}$ facets in presence of a counterion $\mathrm{Na}^{+}$. The presence of oxides $\left(\mathrm{OH}^{-}\right.$or $\left.\mathrm{O}^{2-}\right)$ on the adsorption energy is also evaluated. A negative value corresponds to an energetically favorable adsorption of the halide anions $\mathrm{X}^{-}$.

\begin{tabular}{l|cccc} 
Surface & $\mathrm{Na}^{+} \mathrm{F}^{-}$ & $\mathrm{Na}^{+} \mathrm{Cl}^{-}$ & $\mathrm{Na}^{+} \mathrm{Br}^{-}$ & $\mathrm{Na}^{+} \mathrm{I}^{-}$ \\
\hline $\mathrm{Au}\{111\}$ & -0.94 & -1.09 & -1.15 & -1.30 \\
$\mathrm{Au}\{111\}-\mathrm{OH}^{-}$ & -1.87 & -1.80 & -1.90 & -2.15 \\
$\mathrm{Au}\{111\}-\mathrm{O}^{2-}$ & -2.84 & -2.87 & -2.94 & -3.08
\end{tabular}

Table S2, summarizing the calculated adsorption energies, clearly demonstrates that the adsorption of a halide anions $\mathrm{X}^{-}$on a gold surface, without a counterion in the solution, is energetically unfavorable. This result is not affected by the presence of oxides on the surface.

Table S3 shows that halide anions are stabilized on a gold surface in presence of a counterion $\left(\mathrm{Na}^{+}\right.$in the present case). The adsorption stability of halide anions on gold increases following the sequence $\mathrm{F}^{-}<\mathrm{Cl}^{-}<\mathrm{Br}^{-}<\mathrm{I}^{-}$, in reverse order of the Hofmeister sequence. ${ }^{7,8}$ This result is fully consistent with quantitative adsorption studies. Using an electrochemical quartz crystal microbalance, Lei et al. ${ }^{9}$ have quantitatively assess the adsorption of halide anions $\left(\mathrm{F}^{-}, \mathrm{Cl}^{-}, \mathrm{Br}^{-}\right.$and $\left.\mathrm{I}^{-}\right)$on a highly ordered $\mathrm{Au}(111)$ electrode.

Moreover, table S3 shows that the adsorption energy is larger when oxides are present and the largest for $\mathrm{Au}\{111\} \mathrm{O}^{2-}\left(\mathrm{Au}^{3+}\right)$. The presence of oxides is not a sufficient condition to stabilize halide anions on a gold surface, but in presence of a counterion, oxides can lead to a synergetic effect. 

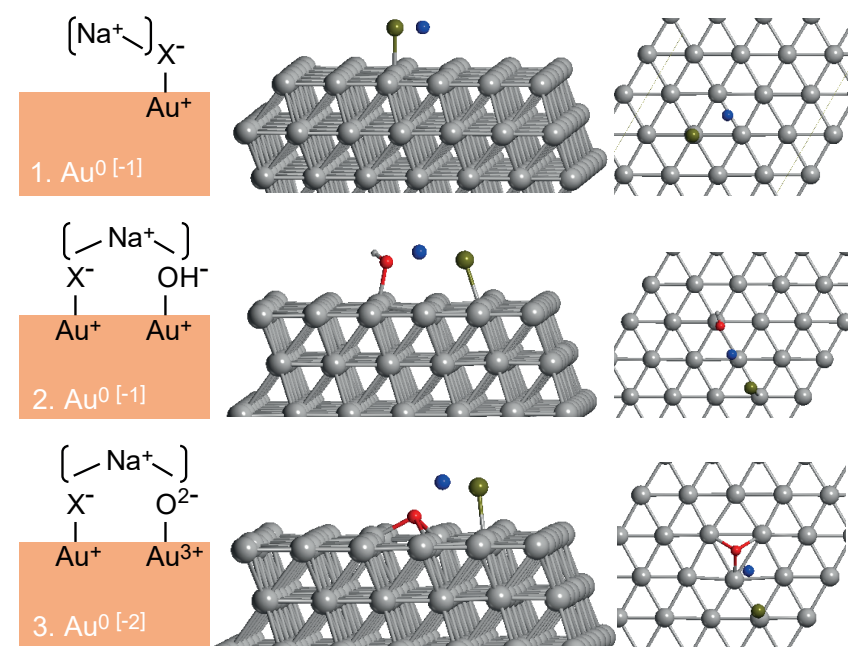

Figure S2: Systems studied in numerical simulation. From left to right, atomic elements involved in the numerical simulation, 3D-view of the crystal structure and top view of the $\{111\}$ facets showing the localisation of the halide anions (dark yellow), oxygen atoms (red), sodium cations (blue), and hydrogen atoms (white) with respect to the gold structure (grey). From top-down, (1) Halide anion $\mathrm{X}^{-}$adsorbed on a gold $\{111\}$ facet, (2) Halide anion $\mathrm{X}^{-}$ and hydroxide adsorbed on a gold $\{111\}$ facet, and (3) Halide anion $\mathrm{X}^{-}$and oxygen $\left(\mathrm{O}^{2-}\right)$ adsorbed on a gold $\{111\}$ facet. Four halide anions has been studied, $\mathrm{F}^{-}, \mathrm{Cl}^{-}, \mathrm{Br}^{-}$and $\mathrm{I}^{-}$. In all case, two simulations has been conducted, one involving a couterion $\mathrm{Na}^{+}$and one without a couterion. The initial charge of gold is given with and without $\mathrm{Na}^{+}$(within bracket in the second case). 


\section{References}

(1) Cumpson, P.; Seah, M. Elastic scattering corrections in AES and XPS .2. Estimating attenuation lengths and conditions required for their valid use in overlayer/substrate experiments. Surf. Interface Anal. 1997, 25, 430-446.

(2) Shard, A. G.; Wang, J.; Spencer, S. J. XPS topofactors: determining overlayer thickness on particles and fibres. Surf. Interface Anal. 2009, 41, 541-548.

(3) Unger, I.; Saak, C.-M.; Salter, M.; Zieger, P.; Patanen, M.; Björneholm, O. Influence of Organic Acids on the Surface Composition of Sea Spray Aerosol. The Journal of Physical Chemistry A 2020, 124, 422-429.

(4) Papagiannouli, I.; Patanen, M.; Blanchet, V.; Bozek, J. D.; de Anda Villa, M.;

Huttula, M.; Kokkonen, E.; Lamour, E.; Mevel, E.; Pelimanni, E.; Scalabre, A.; Trassinelli, M.; Bassani, D. M.; Lévy, A.; Gaudin, J. Depth Profiling of the Chemical Composition of Free-Standing Carbon Dots Using X-ray Photoelectron Spectroscopy. The Journal of Physical Chemistry C 2018, 122, 14889-14897.

(5) Sohn, Y.; Pradhan, D.; Radi, A.; Leung, K. T. Interfacial Electronic Structure of Gold Nanoparticles on Si(100): Alloying versus Quantum Size Effects. Langmuir 2009, 25, 9557-9563.

(6) Lu, Z.; Sham, T.; Norton, P. INTERACTION OF AU ON SI(100) STUDIED BY CORE LEVEL BINDING-ENERGY SHIFTS. Solid State Communications 1993, 85, 957-959.

(7) Cacace, M. G.; Landau, E. M.; Ramsden, J. J. The Hofmeister series: salt and solvent effects on interfacial phenomena. Q. Rev. Biophys. 1997, 30, 241-277.

(8) Andreev, M.; de Pablo, J. J.; Chremos, A.; Douglas, J. F. Influence of Ion Solvation on the Properties of Electrolyte Solutions. J. Phys. Chem. B 2018, 122, 4029-4034. 
(9) Lei, H.-W.; Uchida, H.; Watanabe, M. Electrochemical Quartz Crystal Microbalance Study of Halide Adsorption and Concomitant Change of Surface Excess of Water on Highly Ordered Au(111). Langmuir 1997, 13, 3523-3528. 